\title{
Evaluating the leachate contamination impact of landfills and open dumpsites from developing countries using the proposed Leachate Pollution Index for Developing Countries (LPIDC)
}

\begin{abstract}
The Leachate Pollution Index (LPI) was formulated in 2005 to evaluate the pollution potential of landfill leachate, so that better strategies can be implemented to prevent continuous environmental degradation. As leachate characteristics are dependent on the waste composition, which is notably different between developed and developing countries, the LPI cannot be used to accurately evaluate leachate from all over the world. Hence, using the LPI as a benchmark would yield inaccurate conclusions on the severity of the pollution of these leachates. To address this, we developed an index that is more accurate in determining the pollution impact of leachate in developing countries; The Leachate Pollution Index for Developing Countries (LPIDC). LPIDC was developed after consulting various experts in waste management based in developing countries, who shared their expertise, knowledge and experience to identify parameters that needed to be assessed when evaluating the pollution potential of leachate. To determine the precision of LPIDC, we analysed leachate samples from Malaysian landfills and open dumpsites, and also reviewed leachate data from other developing countries. We then used the data to compare the precision of LPI and LPIDC. The data confirmed that LPIDC provided a more precise evaluation of the pollution impact of leachate in developing countries. This is due to the LPIDC taking into account several important parameters that were overlooked in the LPI, namely landfill liners and leachate volume.
\end{abstract}

Keyword: Pollution impact; Leachate Pollution Index; Waste management; Environmental indices 